\title{
O ESTADO E A GARANTIA DE DIREITOS HUMANOS
}

\author{
Michely Moreira de Souzal \\ Rodrigo Regert ${ }^{2}$ \\ Joel Haroldo Baade \\ Marcos Antônio Maestri Miguel ${ }^{4}$ \\ Gilberto Medeiros Borges Junior \\ Aline Sartorel ${ }^{6}$ \\ Recebido em: 17 jul. 2019 \\ Aceito em: $10 \mathrm{dez} .2019$
}

\section{RESUMO}

Com a formação do Estado, este passou a moldar as necessidades dos cidadãos, preenchendo lacunas e reescrevendo alguns direitos. Mesmo assim, a base da essência humana deve ser preservada, e com a promulgação dos direitos humanos em 1948 torna-se universal o papel do Estado como guardião desses direitos, bem como da dignidade humana. No Brasil surgem os direitos fundamentais positivados apenas no ordenamento na Constituição Federal, sendo princípio norteador no comportamento jurídico. Em razão disso, o presente artigo tem como objetivo refletir sobre o Estado, a Sociedade, os Direitos Humanos e a Dignidade Humana. Para isso, nos aspectos metodológicos, utilizou-se dos seguintes critérios: natureza básica, abordagem qualitativa, caracterizando-se como pesquisa do tipo exploratória e bibliográfica. Conclui-se que os direitos humanos tem suas bases alicerçadas sobre a moral, a política e o direito, e dessa forma é incumbida ao Estado a prerrogativa de garanti-los, independentemente de qualquer situação, uma vez que o próprio Estado surge da outorga do poder dado pelos indivíduos como povo, tornando-se, assim, um organismo vivo, pois é composto de pessoas. No entanto, nada disso tem efeito caso o conjunto dos cidadãos não tomar para si a parte que lhe cabe, que é a responsabilidade de respeitar e cumprir os direitos humanos.

Palavras-chave: Estado. Constituição Federal. Dignidade Humana. Direitos Fundamentais.

\section{THE STATE AND THE GUARANTEE OF HUMAN RIGHS}

ABSTRACT: With the formation of the State, it began to shape the needs of citizens, filling gaps and rewriting certain rights. Even so, the basis of human essence must be preserved, and with the promulgation of human rights in 1948 the role of the State as guardian of these rights as well as of human dignity becomes universal. In Brazil, fundamental rights are only positivized in the Federal Constitution, being a guiding

\footnotetext{
${ }^{1}$ Bacharel em Administração e acadêmica do curso de Direito na Universidade Alto Vale do Rio do Peixe (UNIARP). E-mail: michellysouza490@gmail.com

${ }^{2}$ Mestre em Desenvolvimento e Sociedade pela UNIARP. Professor de Ensino Superior no Serviço Nacional de Aprendizagem Comercial (SENAC/Videira-SC) e na UNIARP. E-mail: regert.rodrigo@gmail.com

${ }^{3}$ Doutor. Docente e pesquisador do Programa de Pós-Graduação em Desenvolvimento e Sociedade e do Programa Profissional em Educação da UNIARP. E-mail: baadejoel@gmail.com

${ }^{4}$ Especialista em Gestão Pública na UNIARP e Direto Material e Processual do Trabalho Universidade do Oeste de Santa Catarina (UNOESC). Professor de Ensino Superior na UNIARP. E-mail: marcosmiguel@hbinfo.com.br ${ }^{5}$ Mestrando em Desenvolvimento e Sociedade na UNIARP. Professor de Ensino Superior no SENAC/Videira e na UNIARP. E-mail: gilberto93.junior21@gmail.com

${ }^{6}$ Mestra em Educação pela Universidade do Oeste de Santa Catarina. Coordenadora de Educação Básica e Superior no SENAC/Videira-SC. E-mail: sartorel.aline@gmail.com
} 
principle in legal behavior. Because of this, this article aims to reflect on the State, Society, Human Rights and Human Dignity. For this, in the methodological aspects, the following criteria were used: basic nature, qualitative approach, being characterized as research of the exploratory and bibliographic type. It is concluded that human rights have their bases based on morality, politics and law, and in this way the State is given the prerogative to guarantee them, regardless of any situation, since the State itself arises from the granting of the power given by individuals as a people, thus becoming a living organism because it is composed of people. However, none of this will have an effect if all citizens do not take their own share of responsibility, which is respecting and fulfilling human rights

Keywords: State. Federal Constitution; Human Dignity; Fundamental Rights.

\section{INTRODUÇÃO}

O Brasil passa por um momento sem precedentes de acesso à informação e ao judiciário, tornando-se imprescindível que o conhecimento e o discernimento dos homens e mulheres sejam mais assertivos possíveis no momento de utilizar e analisar as funções do Estado.

Rever a história dos direitos humanos permite uma profunda reflexão sobre as bases da sociedade e a forma em que ela organizada, pois esta é feita de pessoas e essas mudam constantemente, sendo assim, o Estado é uma organização viva que necessita se adaptar a cada momento da história.

No entanto, cabe ressaltar, que a dignidade humana é intrínseca ao ser no seu estado natural e por isso deve ser sempre respeitada independente do momento histórico, tendo o Estado como fomentador do desenvolvimento dos potenciais de cada indivíduo. Conhecendo as bases de toda a estrutura pode-se apropriar a cada parte da engrenagem sua devida responsabilidade, objetivando o bem coletivo.

Diante disso, o presente artigo tem como objetivo refletir sobre o Estado, a Sociedade, os Direitos Humanos e a Dignidade Humana. Para isso, a pesquisa foi de natureza básica, sua abordagem deu-se de forma qualitativa, o objetivo desenrolou-se de modo exploratório e o procedimento metodológico ocorreu de maneira bibliográfica.

O texto está estruturado em três pontos principais: no primeiro será abordado a ideia de Estado e Sociedade; no segundo os Direitos Humanos e no terceiro a própria Dignidade Humana.

\section{ESTADO E SOCIEDADE}

O Estado como conhecemos atualmente se consolidou pela necessidade de um conjunto de indivíduos. O Estado, entendido como um ordenamento político de uma comunidade, surge da dissolução da comunidade primitiva fundada sobre laços de parentesco e da formação de comunidades maiores derivadas da união de vários grupos familiares por razões de sobrevivência interna, ou seja, o 
sustento, pois precisavam de terras para o cultivo de alimentos e externa, como defesa a outros grupos (BOBBIO, 1987).

O Estado é uma sociedade política, ou seja, uma sociedade criada a partir da vontade humana, onde o objetivo é a concretização dos fins daquelas organizações mais amplas que o ser humano teve necessidade de criar para enfrentar o desafio da natureza e das outras sociedades rivais. A evolução trouxe consigo os vínculos sociológicos, sendo que o Estado apresenta vínculos de natureza jurídica (BASTOS, 1999).

O antecedente mais antigo que traz afirmação sobre a natureza social do ser humano encontra-se no século IV a.C., com Aristóteles de que "o homem é naturalmente um animal político". Sendo que os animais se agrupam por mero instinto, pois o homem, entre todos os animais, é o único que possui razão e consciência, o sentimento de bem ou mal, do justo e do injusto (DALLARI, 2016).

A consciência humana, fez com que as pessoas celebrassem contrato, que é a mutua transferência de direitos, e por esse ato se estabelece a vida social, cuja preservação, entretanto, depende da existência de um poder visível, que mantenha os indivíduos dentro dos limites consentidos e os obrigue, pela coerção, a cumprir seus compromissos, bem como a observância das leis da natureza. Esse poder visível é o Estado instituído pelo homem natural para sua proteção e defesa (DALLARI, 2016).

A sociedade tem como finalidade o bem comum, assim ela busca a criação de condições que permitam a cada indivíduo e a cada grupo social a consecução de seus respectivos objetivos particulares. Quando uma sociedade esta organizada de tal modo que só promove o bem de uma parte de seus integrantes, é sinal de que ela esta mal organizada e afastadas dos objetivos que justificam sua existência (DALLARI, 2016).

O constitucionalismo sempre esteve presente ao longo da evolução do direito positivo, sendo na antiguidade a Lei do Senhor; democracia-direta nas cidades estados gregas; na Idade Média com a Magna Carta de 1215; na Idade Moderna com os pactos e forais ou cartas de franquia; o constitucionalismo Norte-Americano com a Carta outorgada pelo rei Carlos II em 1662, seguido da constituição da confederação dos Estados Americanos em 1781; constitucionalismo moderno com a constituição norte americana de 1787 e constituição francesa de 1791. No contemporâneo constitucionalismo globalizado, ou seja, a constituição programática, tendo-se como exemplo a Constituição Brasileira de 1988, ainda com a proteção aos direitos de fraternidade ou solidariedade (LENZA, 2016).

A sociedade é uma instituição em constante evolução e transformação. As tecnologias desenvolvidas surgem com novas formas de vínculos e de organização social, sendo imprescindível a adaptação e ajustes, se possível, na mesma velocidade. Fundamentado na Constituição Federal de 
1988, o princípio da dignidade humana é um princípio-matriz de todos os direitos fundamentais. Sendo a constituição o centro de todo o sistema jurídico, marcada pela intensa carga valorativa. A lei de modo geral deve não so observar a forma prescrita, mas acima de tudo, estar em consonância com o seu espírito, o seu caráter axiológico e os seus valores destacados. Dessa forma, a constituição adquire imperatividade, superioridade e centralidade. A partir do momento que os valores são constitucionalizados, o desafio passa a ser encontrar mecanismos para sua efetiva concretização (LENZA, 2016).

Assim o Estado precisa responder normativamente aos problemas reais da sociedade, tendo na sua falta o risco da descrença no próprio sistema jurídico (LENZA, 2016).

\section{DIREITOS HUMANOS}

A conceituação de direitos humanos tem suas raízes fincadas nos campos da moral, da política e do direito. A interdisciplinaridade pode ser extraída da própria denominação dessa espécie de direito: são direitos reivindicáveis em face da condição humana e, por isso, pertencentes a todos os homens e a cada um deles. A condição humana e seus atributos são desenvolvidos pela filosofia moral, por essa razão que se diz que eles correspondem às necessidades humanas essenciais que se traduzem em exigências morais, as quais, pretendem ser garantidos e reconhecidos pelo direito, gerando deveres (BRANDÃO, 2014).

Assim os reflexos dessa condição na limitação da ação do Estado é matéria desenvolvida pela política; na positivação dentro do ordenamento jurídico é matéria do direito. Neste tríplice contexto, os Estados, através da política e do direito, não são instigadores dos direitos humanos, mas sim seus fiadores indispensáveis (BRANDÃO, 2014).

A maioria dos autores considera o antecedente direto mais remoto, das Declarações de Direitos que é Magna Carta da Inglaterra, de 1215. Não havia um caráter universal de direitos inerentes à pessoa humana e oponíveis a qualquer governo, o que ela consagrou foram os direitos dos barões e prelados ingleses, restringindo o poder absoluto dos monarcas. Essa afirmação de direitos feita de forma geral tornou-se a obrigação do rei da Inglaterra no seu relacionamento com os súditos, representando assim um avanço, ficando fixado alguns princípios que mais tarde viriam obter amplo desenvolvimento, alcançando a consagração universal (DALLARI, 2016).

Após a Segunda Guerra Mundial, no ano de 1946, foi iniciado o trabalho para elaboração de um documento que fosse universal dos direitos humanos, sendo aprovado em 1948 pela Assembleia Geral das Nações Unidas, surgindo assim a Declaração dos Direitos Humanos. Na Declaração em seu

preâmbulo são proclamados os direitos fundamentais. É bem expressivo esse termo, pois torna 
evidente que não há concessão ou reconhecimento dos direitos, mas proclamação deles, significando que sua existência, independe de qualquer vontade ou formalidade, são direitos inerentes à natureza humana, nenhuma autoridade tem legitimidade para retirá-los de qualquer indivíduo (DALLARI, 2016).

Os direitos humanos formam um sistema indivisível, interdependente e complementar entre si. As normas se complementam garantindo assim a efetividade plena que elas buscam alcançar. Mesmo estando consagrados em diferentes tratados não retira sua característica de indivisibilidade (CASADO FILHO, 2012).

Os direitos dos homens e das mulheres, por mais fundamentais que sejam, são direitos históricos, ou seja, nascidos em certas circunstâncias, caracterizadas pelas lutas buscando defender as novas liberdades contra velhos poderes e nascidos de modo gradual, não todos de uma vez e nem de uma vez por todas. Nascem quando o aumento do poder do homem sobre o homem que acompanha inevitavelmente o progresso técnico, isto é, o progresso da capacidade do homem de dominar a natureza e os outros homens (BOBBIO, 2004).

Os direitos humanos possuem uma linha evolutiva. Assim, em cada época histórica, se adicionou os direitos e valores julgados importantes no desenvolvimento da sociedade. Sendo então os direitos humanos aberto à evolução, permitindo a inclusão de novos direitos e garantias, conforme a necessidade. No entanto, uma característica intrínseca é a proibição do retrocesso, assim pode-se alterar, bem como, revestir cada direito, nunca retirar (CASADO FILHO, 2012).

As exigências de novos conhecimentos e de novas proteções na passagem da consideração do homem abstrato para o homem evoluído, em suas diversas áreas de vida ou de estágios. Por exemplo, o direito à instrução ou à assistência, são exigências que nascem somente quando são necessidades latentes, e surgem em função da mudança das condições e quando o desenvolvimento técnico permite saná-los (BOBBIO, 2004).

\section{DIGNIDADE HUMANA}

A pessoa natural com suas características, intrinsecamente é dotada de inteligência, consciência e vontade. Há uma dignidade humana que deve ser reconhecida e a preservação desta faz parte dos direitos humanos. $\mathrm{O}$ crescimento econômico e o progresso material de um povo têm um valor negativo se forem conquistados à custa de ofensas da dignidade humana. A pessoa consciente do que é e do que os outros são, consegue perceber a realidade que não teria nascido e sobrevivido sem amparo e a ajuda de muitos. Dai decorre, uma solidariedade natural que resulta da fragilidade do ser humano (DALLARI, 2004). 
Monstequieu, desenvolveu a teoria da separação dos poderes, sendo que um deste deveria agir de forma a limitar a força dos outros dois, estabelecendo-se um relacionamento harmônico e equilibrado. A dignidade estava tão fortemente ligada à ideia de liberdade, de esfera própria do indivíduo na qual o Estado não poderia interferir. A construção do Estado Moderno teve como pressuposto a ideia da dignidade humana. Até os princípios estruturais, como a separação dos poderes e a federação, criados pelas primeiras constituições liberais, são concebidos em termos instrumentais, indo ao encontro da proteção da pessoa humana em face do Estado (GUERRA, 2017).

No entanto, apenas a garantia de liberdade não era suficiente para proporcionar e promover a dignidade humana, tornou-se necessário investir no bem-estar do indivíduo. O Estado devia também promover a dignidade através de prestações positivas ligadas à saúde, educação, trabalho etc., surgiu assim o Estado Social (GUERRA, 2017).

A condição humana traz consigo as atividades fundamentais: labor, trabalho e ação. $\mathrm{O}$ labor é a atividade que corresponde ao processo biológico do ser humano, com crescimento espontâneo, metabolismo e o declínio atrelado às necessidades vitais produzidas e introduzidas pelo lavor no processo de vida de cada indivíduo. O trabalho é a atividade correspondente ao artificialismo da existência humana, o trabalho produz um mundo artificial de coisas, nitidamente diferente de qualquer ambiente natural. A ação corresponde à condição humana da pluralidade, uma vez que não são só os homens e mulheres vivem na terra e habitam o mundo (ARENDT, 2005).

Em resumo o labor assegura não apenas a sobrevivência do indivíduo, mas a vida da espécie. $\mathrm{O}$ trabalho e seu produto emprestam determinada permanência e durabilidade à futilidade da vida mortal e ao caráter efêmero do espaço de tempo ao ser humano. A ação na medida em que se empenha em fundar e preservar corpos políticos, ajusta condições para a história (ARENDT, 2005).

Os homens são seres condicionados, sendo que tudo aquilo com o qual eles entram em contato torna-se imediatamente uma condição de sua existência. No entanto, os homens constantemente criam suas próprias condições (ARENDT, 2005).

Sarlet (2001, p. 60) descreve o conceito jurídico para a dignidade humana:

temos por dignidade da pessoa humana a qualidade intrínseca e distintiva de cada ser humano que o faz merecedor do mesmo respeito e consideração por parte do Estado e da comunidade, implicando, nesse sentido, um complexo de direitos e deveres fundamentais que assegurem a pessoa tanto contra todo e qualquer ato de cunho degradante e desumano, como venham a lhe garantir as condições existenciais mínimas para uma vida saudável, além de propiciar e promover sua participação ativa corresponsável nos destinos da própria existência e da vida em comunhão dos demais seres humanos.

O Estado Social surgiu da necessidade de assegurar as condições mínimas para a vida dos indivíduos, promovendo sua participação ativa na sociedade. Afinal, quanto mais desenvolvido o indivíduo for, menos dependente do Estado ele se torna, interferindo no destino de sua própria 
existência bem como dos demais que tem influência e convívio.

Não se pode confundir direitos humanos com direitos fundamentais, há diferenças entre ambos: os direitos humanos não estão positivados no ordenamento enquanto que os direitos fundamentais estão positivados na Constituição Federal; nos direitos humanos há intenção de universalidade e nos direitos fundamentais há o vínculo apenas do Estado na ordem jurídica concreta; os direitos humanos podem ser vistos como abstratos e os direitos fundamentais são garantias jurídicas concretas e delimitadas, assim podem ser acionadas pelas partes interessadas; os direitos humanos foram concebidos sempre com fins ou programas morais de reforma ou então, de ação política enquanto os direitos fundamentais são garantias jurisdicional (GUERRA, 2017).

Os direitos fundamentais são alicerces de uma sociedade organizada pela política e juridicamente através de uma Constituição Federal. Portanto faz parte da constituição formal e material, evidenciando a importância subjetiva e objetiva para construção de uma ordem dentro da sociedade (GUERRA, 2017).

\section{CONCLUSÃO}

Em uma sociedade eivada de instintos primitivos, constantemente observa-se o desrespeito aos direitos humanos e em consequência à dignidade humana. O Estado como uma sociedade criada com objetivo do bem comum busca desenvolver diretrizes que amenizem tais comportamentos.

Porém, mesmo assim, cabe nesse momento algumas reflexões: O Estado ao buscar o bem comum cria condições para permitir que cada cidadão concretize seus respectivos objetivos particulares, mas como controlar as variáveis impostas pelo contexto individual?

Diante de um mundo em constante e rápida evolução e transformação, como pode o Estado organizar ações em vista do bem comum sendo que seus movimentos são tão mais lentos, seja pelo desvirtuamento da finalidade da máquina pública, ou ainda pelos processos burocráticos de cada engrenagem dessa?

Como pode o Estado ter efetividade para garantir os direitos fundamentais que foram escritos em um momento histórico tão distinto da atualidade?

Tentando dar luz a essas reflexões fica claro que o Estado precisa responder normativamente aos problemas reais da sociedade, e essa é a grande variável imposta pela realidade atual que, se não for resolvida, coloca em risco a crença no próprio sistema jurídico.

Ficou claro também que os direitos humanos têm suas bases alicerçadas sobre a moral, a política e o direito. Sendo incumbido ao Estado a prerrogativa de garanti-los, inclusive o da dignidade 
da pessoa humana. Nesse sentido, o Estado surge da outorga de poder pelos indivíduos enquanto povo, dessa forma o Estado é um organismo vivo, pois é composto de pessoas.

Por fim, nada disso tem valor se o conjunto dos indivíduos não tomar para si a parte que lhe cabe, que é a responsabilidade de respeitar e cumprir os direitos humanos. Conviver em sociedade remete aos princípios básicos da moral e da ética. Talvez seja a solução para que o ordenamento tenha celeridade e flexibilidade diante dos dilemas da sociedade.

\section{REFERÊNCIAS}

ARENDT, Hannah. A Condição Humana. Rio de Janeiro: Forense Universitária, 2005.

BASTOS, Celso Ribeiro. Curso de Teoria do Estado e Ciência Política. São Paulo: Saraiva, 1999.

BOBBIO, Norberto. Estado, Governo e Sociedade: por uma Teoria Geral da Política. Rio de Janeiro: Paz e Terra, 1987.

BOBBIO, Norberto. A Era do Direitos. Rio de Janeiro: Elsevier, 2004.

BRANDÃO, Claudio. Direitos Humanos e Fundamentais em Perspectiva. São Paulo: Atlas, 2014.

CASADO FILHO, Napoleão. Direitos Humanos e Fundamentais. São Paulo: Saraiva, 2012.

DALLARI, Dalmo de Abreu. Direitos Humanos e Cidadania. São Paulo: Moderna, 2004.

GUERRA, Sidney. Direitos Humanos: Curso Elementar. São Paulo: Saraiva, 2017.

LENZA, Pedro. Direito Constitucional Esquematizado. Saraiva - São Paulo: Saraiva, 2016.

SARLET, Ingo Wolfgang. Dignidade da Pessoa Humana e Direitos Fundamentais. 10 ed. Porto Alegre: Livraria do Advogado, 2015. 